\title{
Prohibitin 2 mRNA Downregulation in Breast Cancer Tumor Tissues
}

\author{
Shaghaghi Torkdari $Z^{1}$, Khalaj-Kondori $\mathbf{M}^{1^{*}}$, Hosseinpour Feizi MA $\mathbf{A}^{\mathbf{1}}$ \\ ${ }^{1}$ Department of Animal Biology, Faculty of Natural Sciences, University of \\ Tabriz, Tabriz, Iran
}

\section{Receive: 28/12/2020 Accepted: $14 / 2 / 2021$ \\ "Corresponding Author: khalaj@tabrizu.ac.ir}

Ethics Approval: IR.TABRIZU.REC.1398.016

\begin{abstract}
Introduction: Breast cancer is the most important cause of cancer mortality among women, therefore the study of its causative or aggravating factors seems necessary. In this study, the mRNA levels of the $P H B 2$ gene were evaluated in tumor and adjacent non-tumor tissues of 50 women diagnosed with invasive ductal carcinoma of the breast.
\end{abstract}

Methods: RNX-Plus solution was used to isolate total RNA from tumor and adjacent non-tumor tissues of breast cancer patients. Thereafter, total RNA was converted to cDNA using PrimeScript ${ }^{\mathrm{TM}}$ RT reagent kit. The mRNA levels of $P H B 2$ were quantified by qRTPCR and data were analyzed with a paired-samples $t$ test. Furthermore, ROC curve analysis was performed to evaluate the diagnostic capacity of $P H B 2$ expression in breast cancer tumor tissues.

Results: A significantly lower level of $P H B 2$ mRNA was observed in tumor tissues of breast cancer patients compared with adjacent non-tumor tissues $(\mathrm{P}<0.0001)$. PHB2 mRNA levels showed an approximately 2.5 -fold reduction in tumor tissues compared with normal tissues $(\mathrm{P}=0.001)$. Roc cure analysis showed that PHB2 mRNA level can discriminate tumors from non-tumor tissues with 91.3\% specificity and $64.3 \%$ sensitivity $(\mathrm{AUC}=0.712, \mathrm{P}<0.001)$.

Conclusion: Downregulation of $P H B 2$ in breast cancer patients shows that its mRNA levels can possibly discriminate tumors from non-tumor tissues.

Keywords: Breast Cancer, PHB2, Ductal Carcinoma, Biomarker 


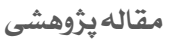
كاهش بيان mRNA يروهيبيتين Y در بافت تومورى سرطان يستان

زينب شقاقى تركدارى'، محمد خلج كندرى"،"، محمدعلى حسينيور فيضى'

اكروه علوم جانورى، دانشكده علوم طبيعى، دانشكاه تبريز، تبريز، ايران
فصلنامه بيمارى هاى بستان ايران

$1 \varepsilon \cdot \cdots \mid \varepsilon(1): V \Lambda-\Lambda \varepsilon$

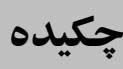

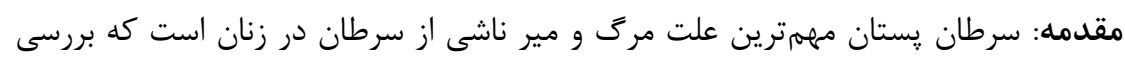

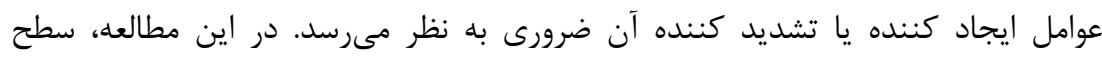
mRNA

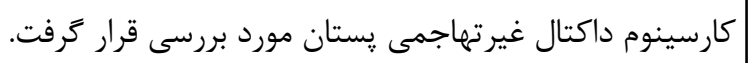
غروش بررسى: محلول RNX-Puls براى استخراج RNA كل از بافت تومورى و و

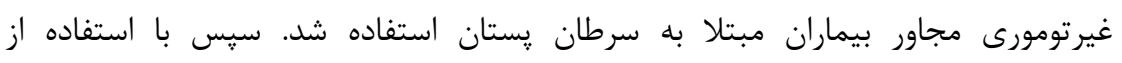
كيت RNA PrimeScriptTM RT كل به CDNA تبديل شد. سطح mRNA

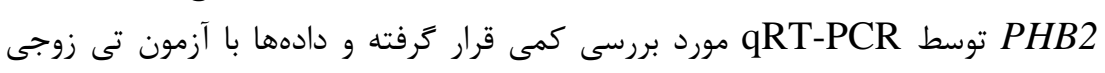

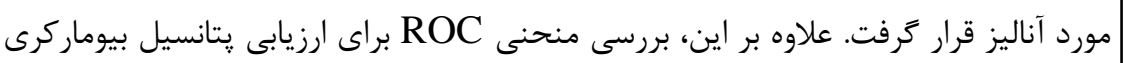
PHB2

يافتهها: سطح پايينى از PHB2 mRNA در بافت تومورى بيماران مبتلا به سرطان پِّتان

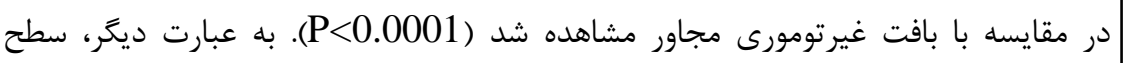
PHB2 mRNA

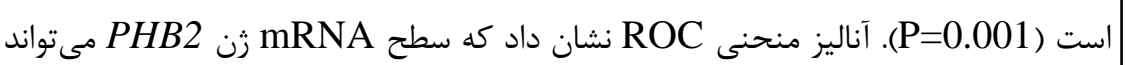

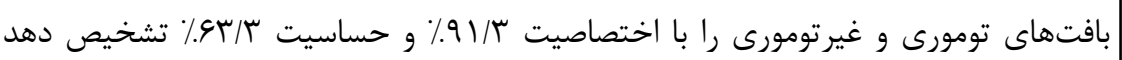
(AUC=0.712, P<0.001) نتيجهَيرى: كاهش سطح mRNA زن PHB2 در بافت تومورى بيماران مبتلا به سرطان

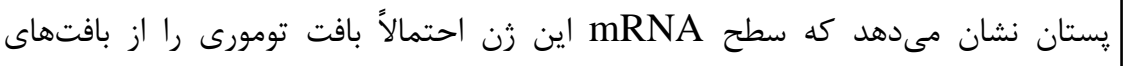
غيرتومورى مجاور مىتواند تمايز دهد. |وازههاى كليدى: سرطان پِتان، PHB2، كارسينوماى داكتال، بيوماركر

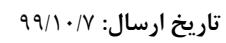

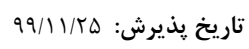

" نويسنده مسئول: khalaj@tabrizu.ac.ir 


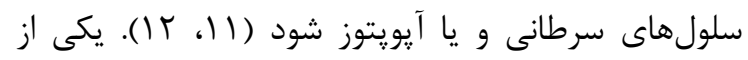

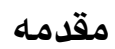

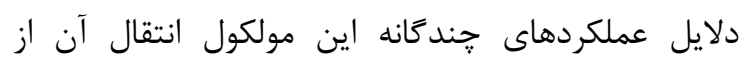

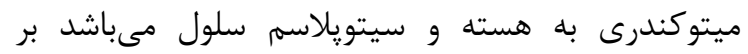

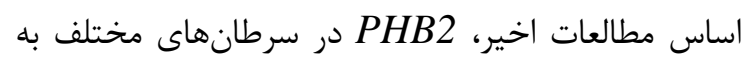

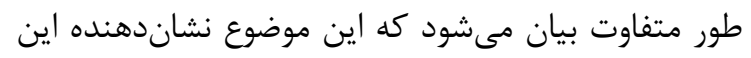

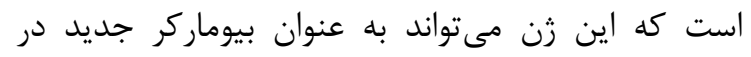

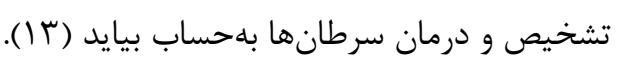
به اين ترتيب هدف مطالعه حاضر، بررسى و و مقايسه سطح mRNA زن غيرتومورى مجاور در زنان مبتلا به سرطان يستان و ون نيز

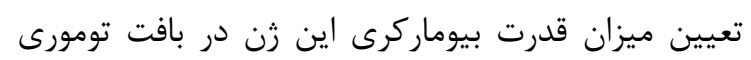

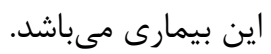

\section{مواد و روشها}

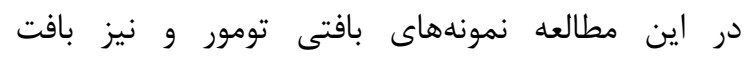

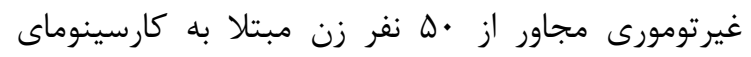

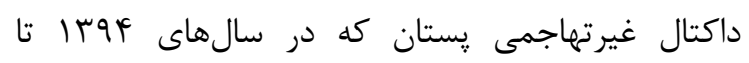

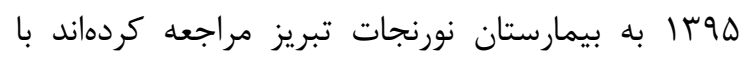
روش نمونه كيرى تصادفى بهدست آمده است. حجم نمونه

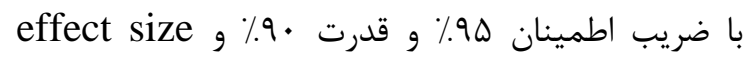

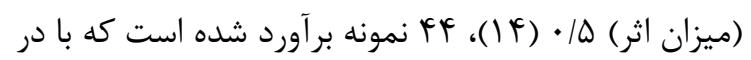

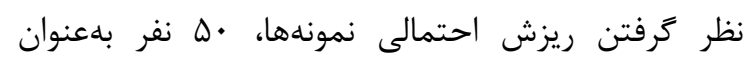

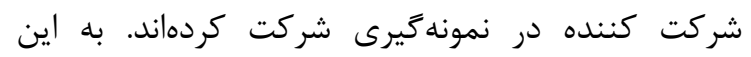

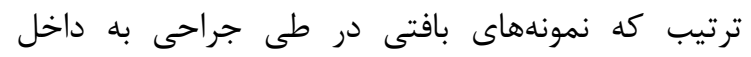

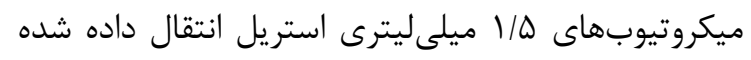

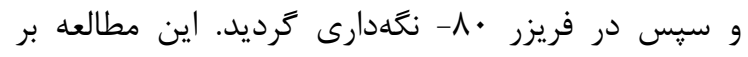
شماره IR.TABRIZU.REC.1398.016 مورد تاييد كميته اخلاق دانشعاه تبريز قرار كرفته و از تمامى بيماران

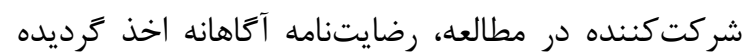

\section{استخراج RNA و رونوشت بردارى معكوس} تام از نمونههاى بافتى بيماران با استفاده از كيت RNX-Plus سانتى گراد نحهدارى شد. براى ارزيابى كميت و كيفيت

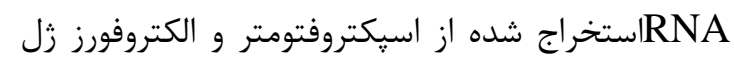
آكارز استفاده شد. سيس رونوشت بردارى معكوس (سنتز به به وسيله كيت PrimeScriptTM انجام شد.

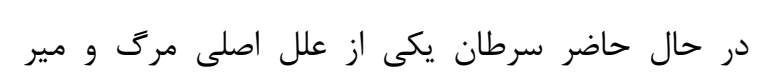

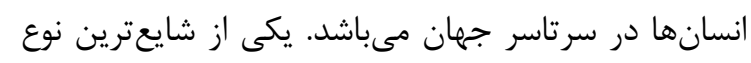

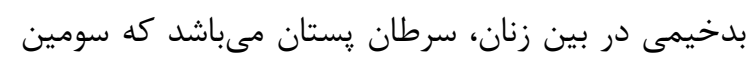

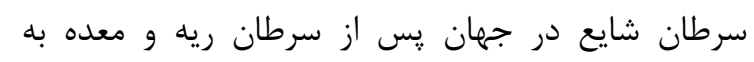

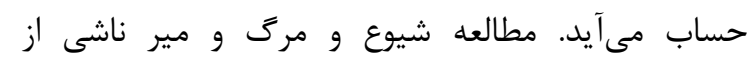

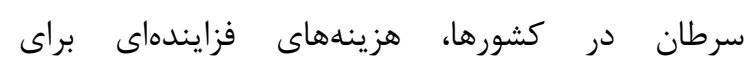
سيستمهاى بهداشتى، به ويزه در كشورهاى با در آمد كم و

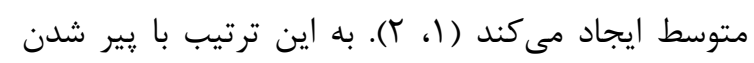

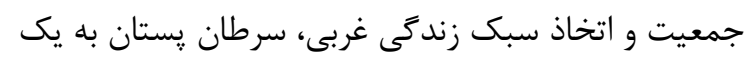

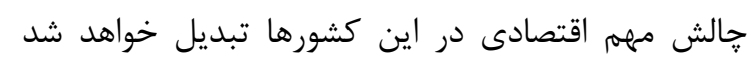

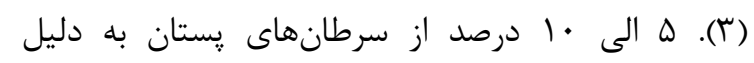

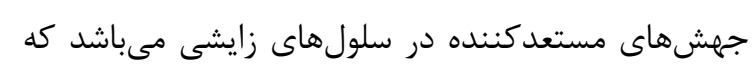

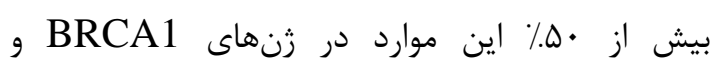

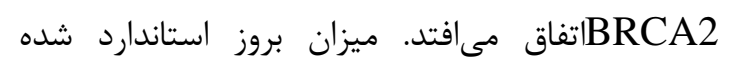

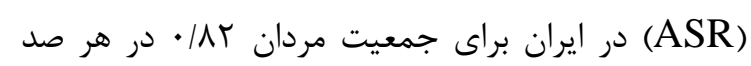

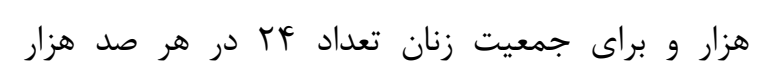

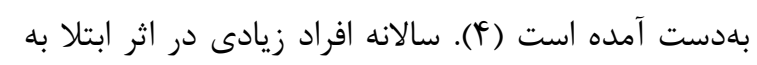

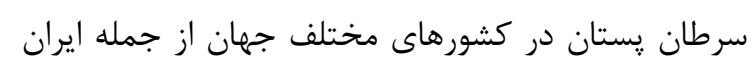

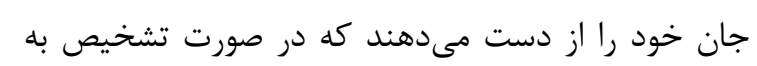

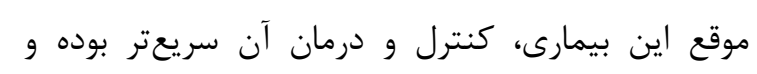

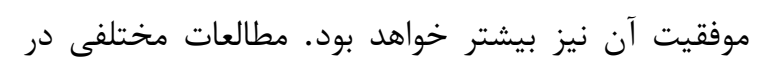
جهت شناسايى عوامل انكوزنى و فاكتورهاى مهاركننده

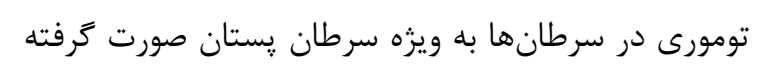

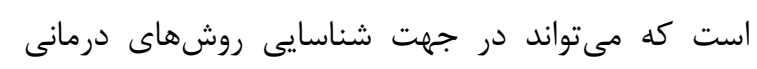

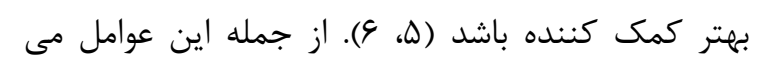
توان به خانواده زنهاى PHB (يروهيبيتينها) اشاره كرد.

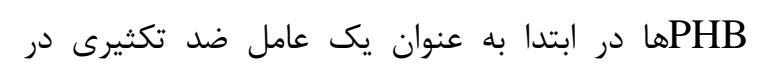

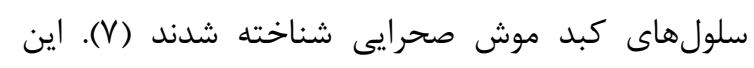

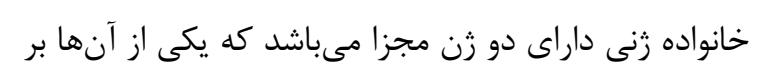

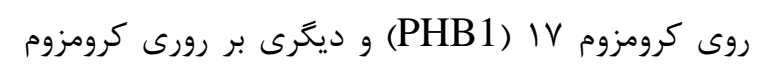

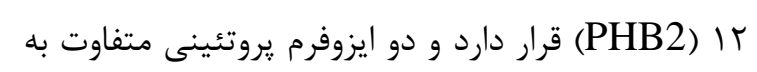

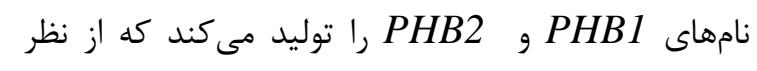
تكاملى حفاطت شده هستند (N). ميانكنش اين دو دو

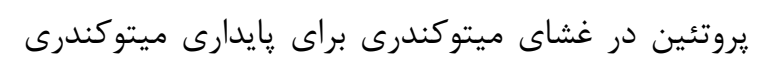

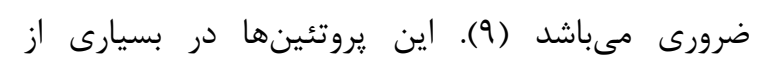

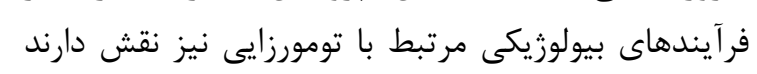

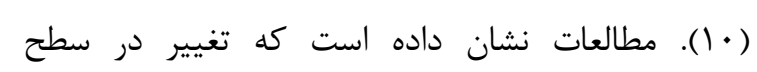
mRNA 


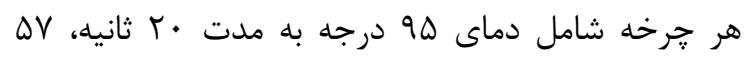

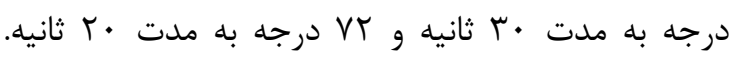
GAPDH

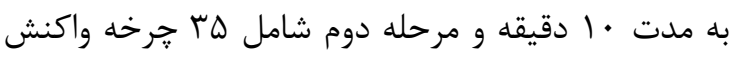

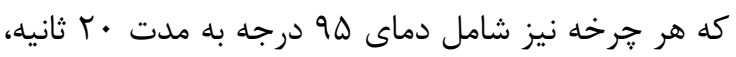

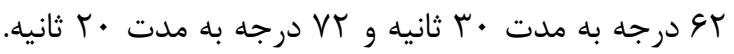

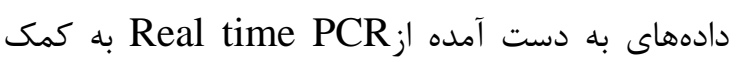
و Graph Pad Prism ، MedCalc

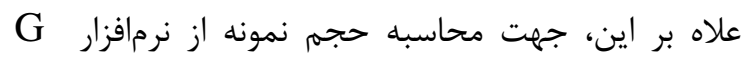
Power

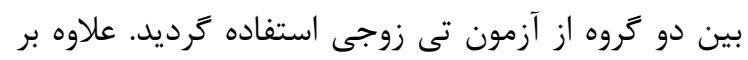

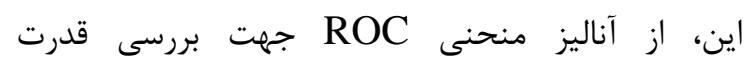

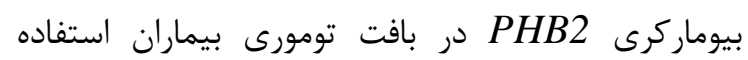

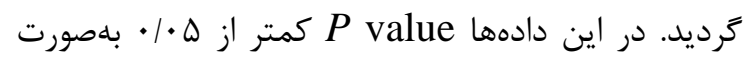
معنى دار تعريف شده است.
واكنش Real-time PCR

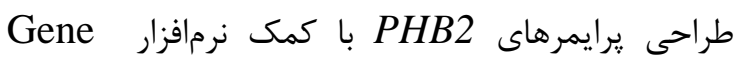
Runner و سايت NCBI انجام شد كه در جدول نشان داده است.

به منظور تكثير زن و بررسى كمى بيان، واكنش Real

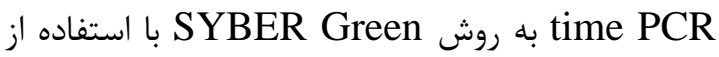

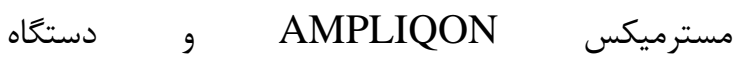
حاصل حاصل صورت كرفت. در اين روش زن هدف با زن كنترل داخلى

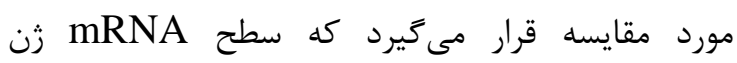
PHB2

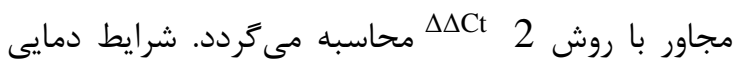
واكنش براى زن رو PHB2 و

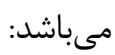

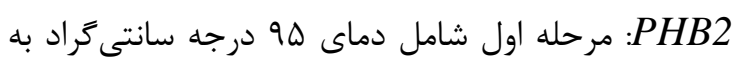

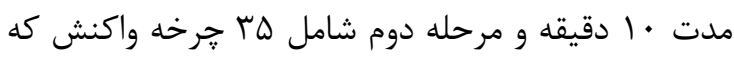

جدول ا: مشخصات ڤرايمرهاى استفاده شده در qPCR

\begin{tabular}{|c|c|c|c|}
\hline \multirow[t]{2}{*}{ طول محصول (bp) } & \multicolumn{2}{|c|}{ توالى برايمرها ('3-3'5) } & \multirow{2}{*}{ 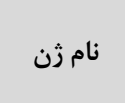 } \\
\hline & Reverse & Forward & \\
\hline 175 & GCTGGCTCCTCAAAAACTG & GCCACATCACAGAATCGTATC & PHB2 \\
\hline 204 & GTCCACCACCCTGTTGCTGTAG & AAGAAGGTGGTGAAGCAGGCGT & GAPDH \\
\hline
\end{tabular}

Relative) زغييرات مربوط به بافتههـا (expression علاوه بر اين، با استفاده از روش

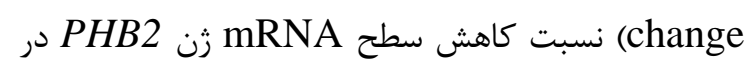

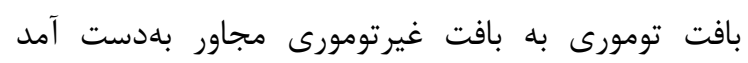

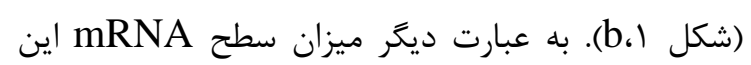

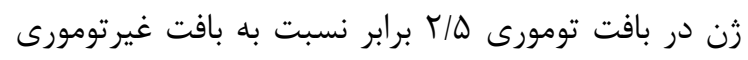

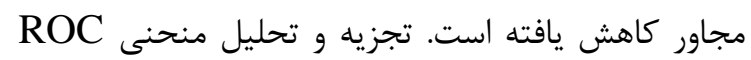

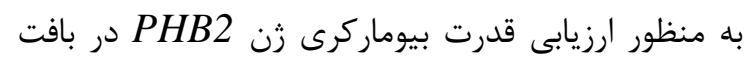

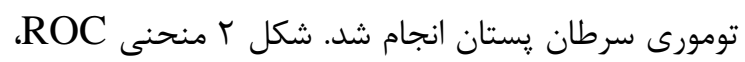
AUC

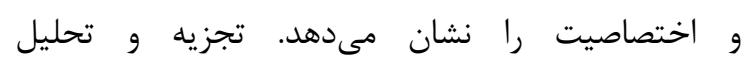

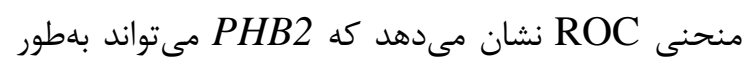

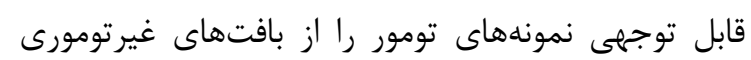
تشخيص دهد (P<0.001). در مجموع ·له بيمار مبتلا به سرطان يستان در اين

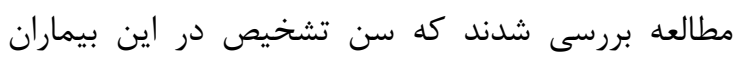

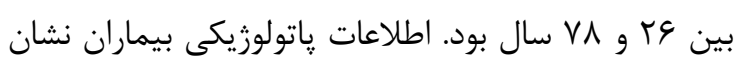

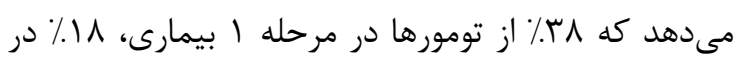

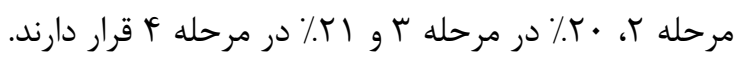

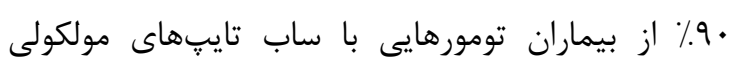

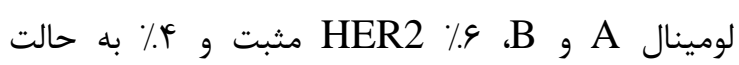
سه كانه منفى (Triple-Negative) دارند. علاوه بر اين، وجود متاستاز در غدد لنفاوى بr آ از بيماران مشاهده شده است. سطح mRNA زن بافتى تومورى و حاشيه تومور مورد بررسى قرار گرفت.

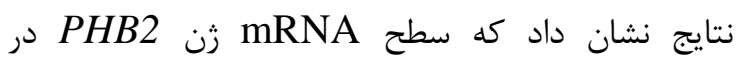
بافتهاى تومورى در مقايسه با بافتهاى غيرتومورى دان

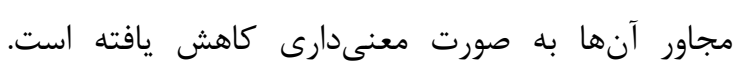


a

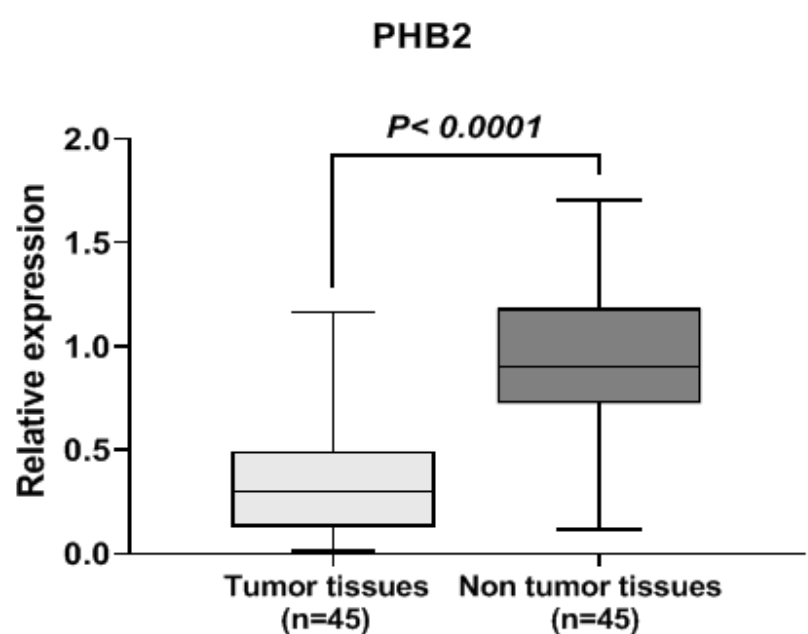

b

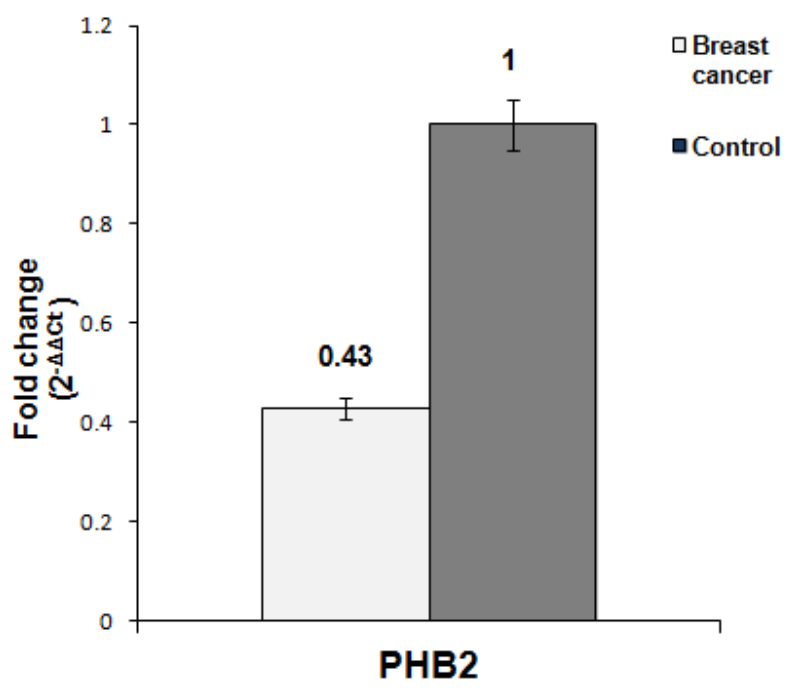

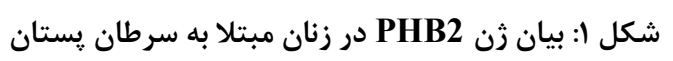

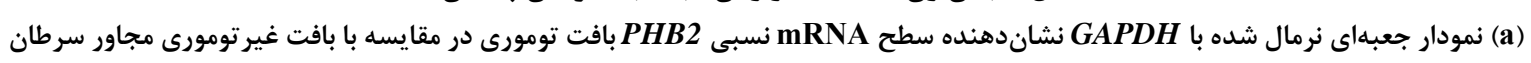

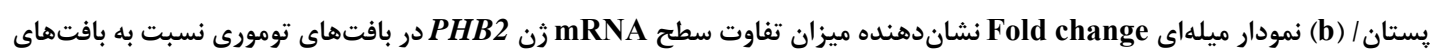
غير تومورى

PHB2

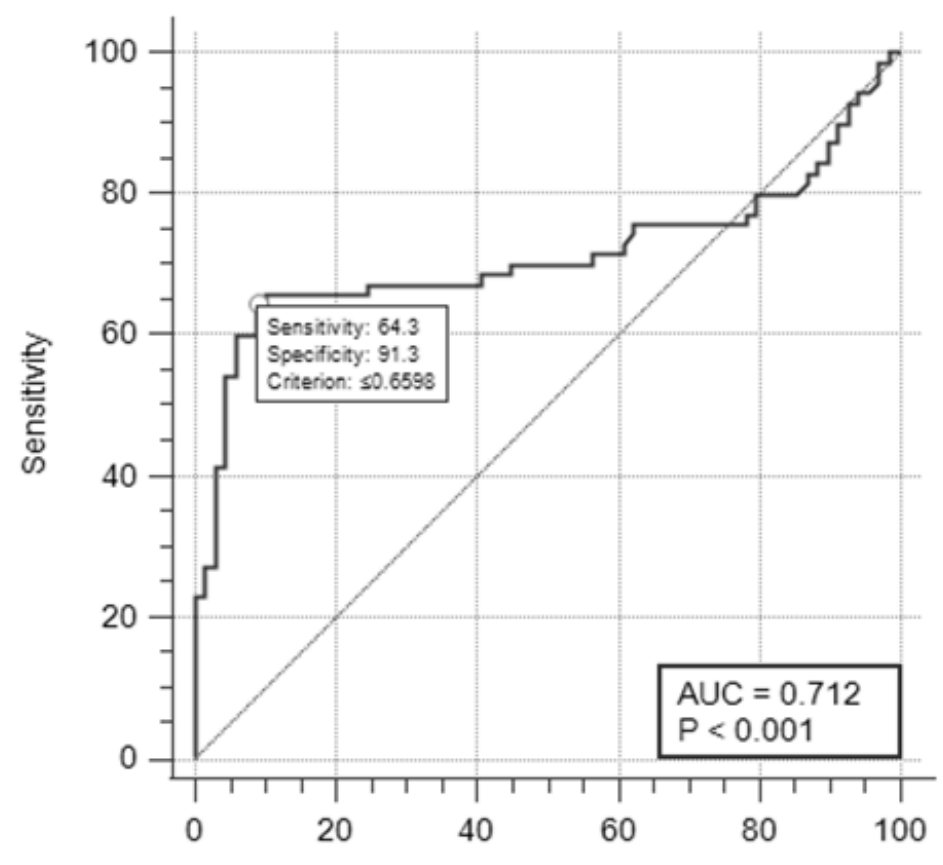

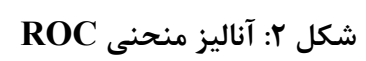

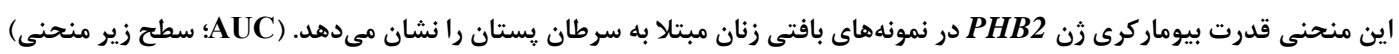


استروزنى آلفا منجر به افزايش رشد سلول هاى سرطانى

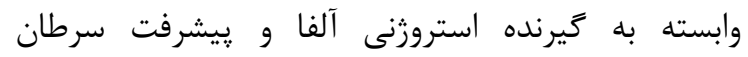

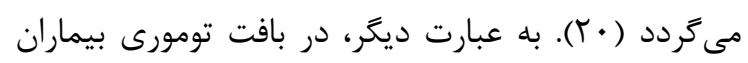

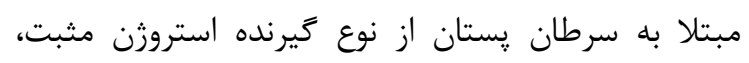

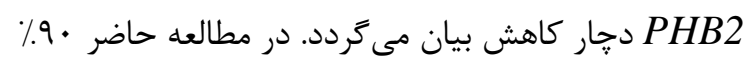

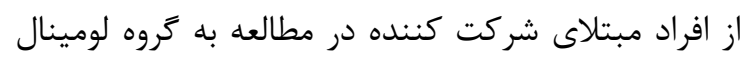

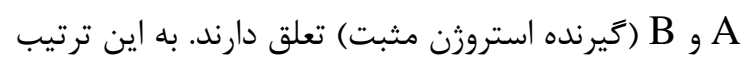

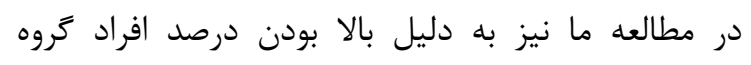

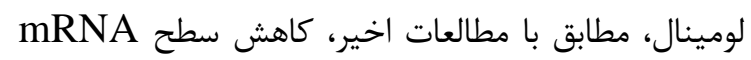
زن PHB2 در بافت تومورى نسبت به بافت غيرتومورى مئح

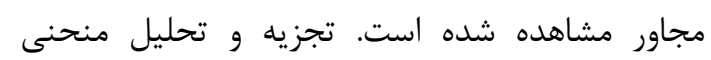

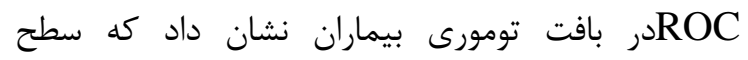
mRNA

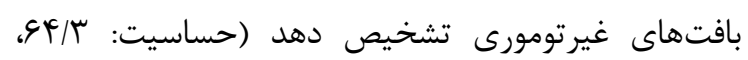

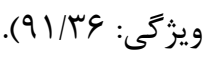

\section{نتيجهكيرى}

سطح mRNA زن PHB2 در نمونههاى بافتى تومورى

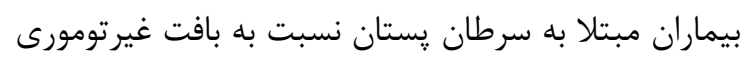

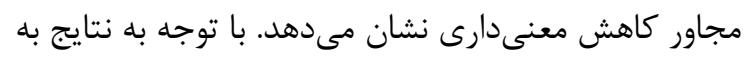

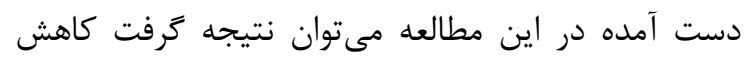

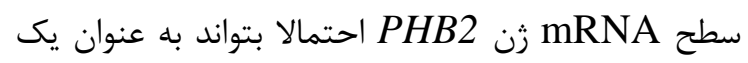

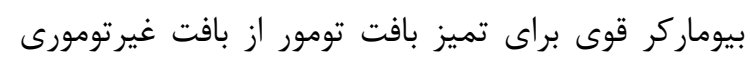

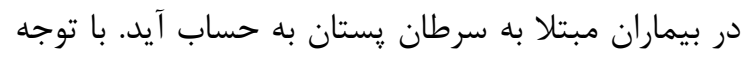

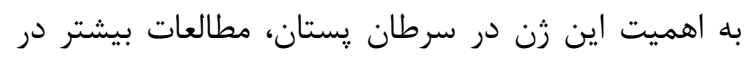

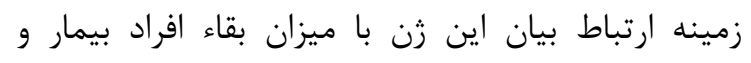

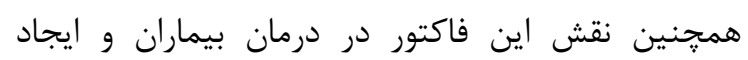
روشهاى درمانى موثر ضرورى بلنظر مىرسد.

تشكر و قدردانى از تمامى بيماران شركت كننده در اين مطالعه كمال تشكر و سياس را داريم.

\section{تعارض منافع}

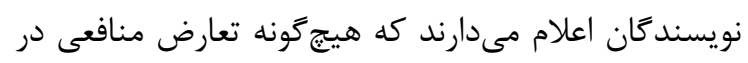
مطالعه حاضر وجود ندارد.

\section{بحث}

PHB2 كه با نامهاى BAP37 و مEA نيز شناخته مىشود، يك يروتئين جند عملكردى مى باشد. اين مولكول

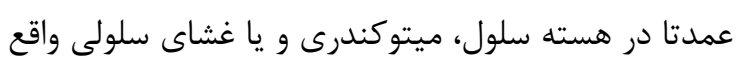

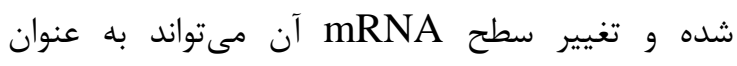

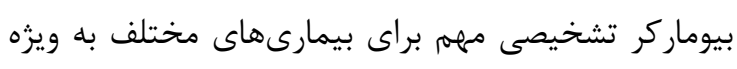

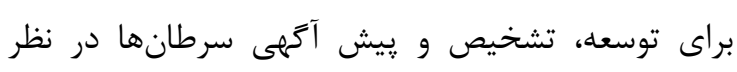

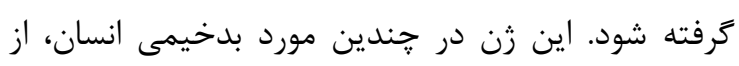

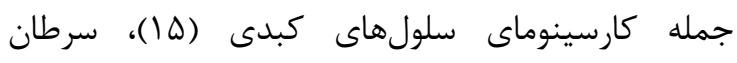

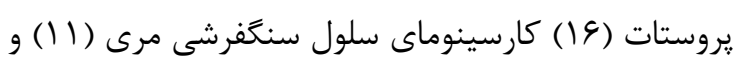

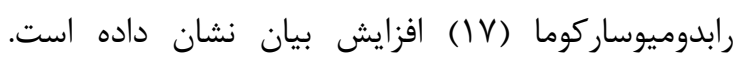

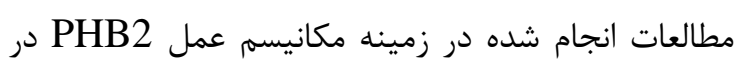

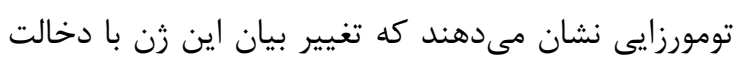

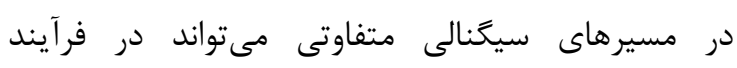

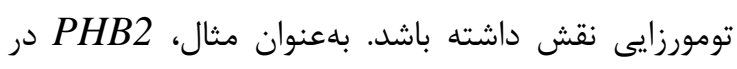

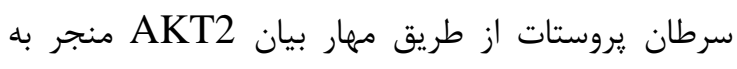

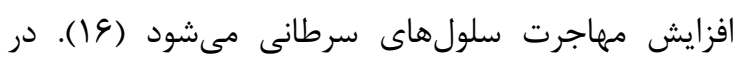

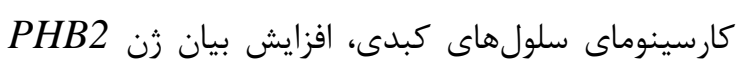

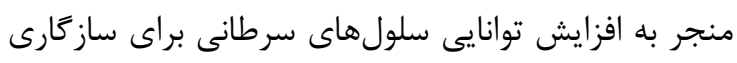
با محيطهاى كم اكسيزن و نيز مقاومت در برابر آيويتوز

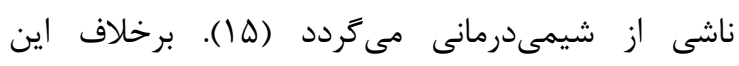
مطالعات، جندين گزارش ديكر نشان دادهاند كه كاهش

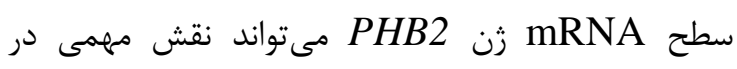
تهاجم و متاستاز آدنوكارسينوماى معده (1)

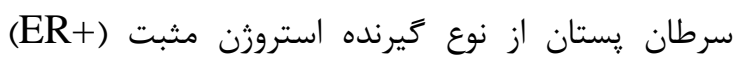

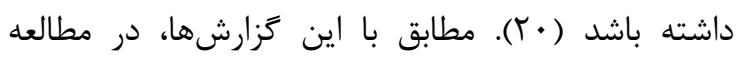

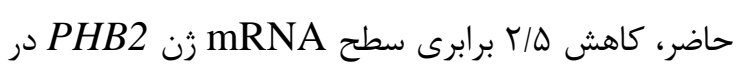

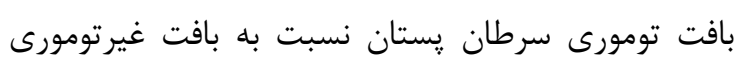

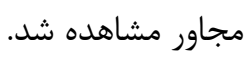

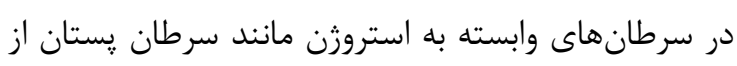

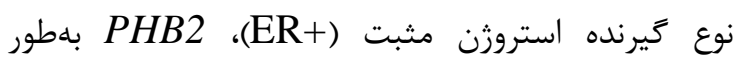

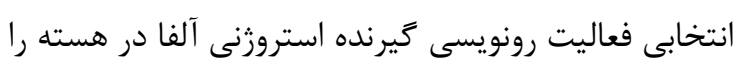

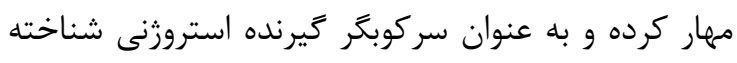

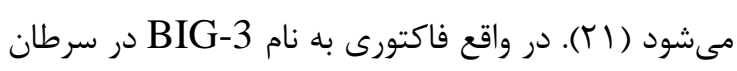

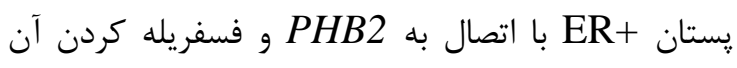

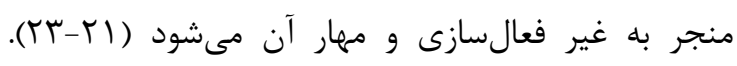
بنابراين كاهش ميزان PHB2 و عدم عدم اتصال آن به كَيرنده 


\section{References}

1. Bray F, Jemal A, Grey N, Ferlay J, Forman D. Global cancer transitions according to the Human Development Index (2008-2030): a population-based study. The Lancet Oncology. 2012; 13(8):790-801.

2. Forouzanfar MH, Foreman KJ, Delossantos AM, Lozano R, Lopez AD, Murray CJL, et al. Breast and cervical cancer in 187 countries between 1980 and 2010: a systematic analysis. The Lancet. 2011; 378(9801):1461-84.

3. Toriola AT, Colditz GA. Trends in breast cancer incidence and mortality in the United States: implications for prevention. Breast Cancer Research and Treatment. 2013; 138(3): 665-73.

4. Abachizadeh K, Moradi-Kouchi A, GhanbariMotlagh A, Kousha A, Shekarriz-Foumani R, Erfani A. Breast cancer in Iran: Levels, variations and correlates. Community Health (Salāmat-i ijtimā̄i). 2018; 5(1):11-21.

5. Lee EY, To H, Shew JY, Bookstein R, Scully $\mathrm{P}$, Lee WH. Inactivation of the retinoblastoma susceptibility gene in human breast cancers. Science. 1988; 241(4862):218-21.

6. T'Ang A, Varley JM, Chakraborty S, Murphree AL, Fung YK. Structural rearrangement of the retinoblastoma gene in human breast carcinoma. Science. 1988; 242(4876):263-6.

7. McClung JK, Danner DB, Stewart DA, Smith JR, Schneider EL, Lumpkin CK, et al. Isolation of a cDNA that hybrid selects antiproliferative mRNA from rat liver. Biochemical and Biophysical Research Communications. 1989; 164(3): 1316-22.

8. Mishra S, Murphy LC, Nyomba BL, Murphy LJ. Prohibitin: a potential target for new therapeutics. Trends Mol Med. 2005; 11(4): 192-7.

9. Nijtmans LG, de Jong L, Artal Sanz M, Coates PJ, Berden JA, Back JW, et al. Prohibitins act as a membrane-bound chaperone for the stabilization of mitochondrial proteins. EMBO J. 2000; 19(11):2444-51.

10. Fu P, Yang Z, Bach LA. Prohibitin-2 binding modulates insulin-like growth factor-binding protein-6 (IGFBP-6)- induced rhabdomyosarcoma cell migration. J Biol Chem. 2013; 288(41):29890-900.

11. Cai XW, Yu WW, Yu W, Zhang Q, Feng W, Liu MN, et al. Tissue-based quantitative proteomics to screen and identify the potential biomarkers for early recurrence/metastasis of esophageal squamous cell carcinoma. Cancer Med. 2018; 7(6):2504-17.
12. Zhang Y, Wang LN, Lin YN, Xing YX, Shi $\mathrm{Y}$, Zhao $\mathrm{J}$, et al. The novel long noncoding RNA C283070 is involved in the transition of LNCaP cells into androgen-independent cells via its interaction with PHB2. Asian J Androl. 2018; 20(5):511-7.

13. Kuramori C, Azuma M, Kume K, Kaneko Y, Inoue A, Yamaguchi Y, et al. Capsaicin binds to prohibitin 2 and displaces it from the mitochondria to the nucleus. Biochem Biophys Res Commun. 2009; 379(2):519-25.

14. Cohen J. Statistical power analysis for the behavioral sciences: Academic press; 2013.

15. Cheng J, Gao F, Chen X, Wu J, Xing C, Lv Z, et al. Prohibitin-2 promotes hepatocellular carcinoma malignancy progression in hypoxia based on a label-free quantitative proteomics strategy. Mol Carcinog. 2014; 53(10):820-32.

16. Shen Y, Gao Y, Yuan H, Cao J, Jia B, Li M, et al. Prohibitin-2 negatively regulates AKT2 expression to promote prostate cancer cell migration. Int J Mol Med. 2018; 41(2):114755.

17. Egas-Bejar D, Huh WW. Rhabdomyosarcoma in adolescent and young adult patients: current perspectives. Adolesc Health Med Ther. 2014; 5:115-25.

18. Jang JS, Cho HY, Lee YJ, Ha WS, Kim HW. The differential proteome profile of stomach cancer: identification of the biomarker candidates. Oncol Res. 2004; 14(10):491-9.

19. Liu T, Tang H, Lang Y, Liu M, Li X. MicroRNA-27a functions as an oncogene in gastric adenocarcinoma by targeting prohibitin. Cancer Lett. 2009; 273(2):233-42.

20. Wanjin H, Kim N-H, Yoshimaru T, Chen YA, Matsuo T, Komatsu M, et al. BIG3 Inhibits the Estrogen-Dependent Nuclear Translocation of PHB2 via Multiple Karyopherin-Alpha Proteins in Breast Cancer Cells. Plos One. 2015; 10(6):e0127707.

21. Chigira T, Nagatoishi S, Tsumoto K. Differential binding of prohibitin-2 to estrogen receptor $\alpha$ and to drug-resistant ER $\alpha$ mutants. Biochemical and Biophysical Research Communications. 2015; 463(4):726-31.

22. Yoshimaru T, Komatsu M, Matsuo T, Chen Y-A, Murakami Y, Mizuguchi $\mathrm{K}$, et al. Targeting BIG3-PHB2 interaction to overcome tamoxifen resistance in breast cancer cells. Nature Communications. 2013; 4(1).

23. Yoshimaru T, Ono M, Bando Y, Chen YA, Mizuguchi K, Shima H, et al. A-kinase anchoring protein BIG3 coordinates oestrogen signalling in breast cancer cells. Nat Commun. 2017; 8:15427. 
